\title{
Metabolic and clinical comparative analysis of treadmill six-minute walking test and cardiopulmonary exercise testing in obese and eutrophic women*
}

\author{
Análise clínica e metabólica comparativa entre o teste de caminhada de seis \\ minutos e o teste de exercício cardiopulmonar em mulheres obesas e eutróficas
}

Luciana Di Thommazo-Luporini', Soraia P. Jürgensen', Viviane Castello-Simões', Aparecida M. Catai', Ross Arena², Audrey Borghi-Silva

\begin{abstract}
Background: Impaired exercise tolerance is directly linked to decreased functional capacity as a consequence of obesity. Objectives: To analyze and compare the cardiopulmonary, metabolic, and perceptual responses during a cardiopulmonary exercise test (CPX) and a treadmill six-minute walking test (tread6MWT) in obese and eutrophic women. Methods: Twenty-nine female participants, aged 20-45 years were included. Fourteen were allocated to the obese group and 15 to the eutrophic group. Anthropometric measurements and body composition assessment were performed. Results: In both tests, obese women presented with significantly higher absolute oxygen uptake, minute ventilation, and systolic and diastolic blood pressure; they also presented with lower speed, distance walked, and oxygen uptake corrected by the weight compared to eutrophics. During the maximal exercise test, perceived dyspnea was greater and the respiratory exchange ratio was lower in obese subjects compared to eutrophics. During the submaximal test, carbon dioxide production, tidal volume, and heart rate were higher in obese subjects compared to eutrophic women. When analyzing possible correlations between the CPX and the tread6MWT at peak, there was a strong correlation for the variable heart rate and a moderate correlation for the variable oxygen uptake. The heart rate obtained in the submaximal test was able to predict the one obtained in the maximal test. Bland-Altman plots demonstrated the agreement between both tests to identify metabolic and physiological parameters at peak exercise. Conclusions: The six-minute walking test induced ventilatory, metabolic, and cardiovascular responses in agreement with the maximal testing. Thus, the six-minute walking test proves to be important for functional evaluation in the physical therapy routine.
\end{abstract}

Keywords: obesity; exercise test; physical fitness; physical therapy.

\section{Resumo}

Contextualização: A reduzida tolerância ao exercício está relacionada à diminuída capacidade funcional consequente da obesidade. Objetivos: Analisar e comparar respostas cardiopulmonares, metabólicas e subjetivas durante um teste de esforço cardiopulmonar e um teste de caminhada de seis minutos na esteira em mulheres obesas e eutróficas. Métodos: Foram incluídas 29 mulheres com idades entre 20 e 45 anos. Catorze voluntárias foram alocadas no grupo de obesas e 15, no grupo de eutróficas. Foram realizadas medidas antropométricas e de composição corporal. Resultados: Em ambos os testes, as obesas apresentaram maiores valores de consumo absoluto de oxigênio, ventilação-minuto e pressão arterial sistólica e diastólica; ainda apresentaram menor velocidade de caminhada, distância percorrida e consumo de oxigênio relativo, quando comparadas com as eutróficas. Durante o teste máximo de exercício, a dispneia percebida foi maior e o quociente respiratório menor nas obesas em relação às eutróficas. Durante o teste submáximo, produção de dióxido de carbono, volume corrente e frequência cardíaca foram maiores nas obesas, comparadas às eutróficas. Houve forte correlação entre a frequência cardíaca e moderada correlação entre o consumo de oxigênio no pico dos testes. A frequência cardíaca obtida no teste submáximo aplicado foi capaz de predizer a frequência cardíaca obtida no teste máximo.

\footnotetext{
'Physical Therapy Department, Nucleus of Research in Physical Exercise, Universidade Federal de São Carlos (UFSCar), São Carlos, SP, Brazil

2Department of Orthopaedics and Rehabilitation, Physical Therapy Program and Department of Internal Medicine, Division of Cardiology, University of New Mexico School of Medicine, Albuquerque, New Mexico, United States of America

*L. Di Thommazo-Luporini, S. Pilon Jürgensen, V. Castello, C. Negrão Dias, R. Luís Luporini, J. Carlos Bonjorno-Júnior, C. Ricardo de Oliveira, A. Maria Catai, A. Borghi-Silva. Comparative analysis of cardiopulmonary and clinical responses to six minute walking test and maximal exercising test in obese women. Eur Respir J. 2011 Sept;38(Suppl55):862s-863s.

Correspondence to: Luciana Di Thommazo, Laboratório de Fisioterapia Cardiopulmonar, Núcleo de Pesquisa em Exercício Físico, Universidade Federal de São Carlos, Rod. Washington Luis, km 235, CEP 13565-905, São Carlos, SP, Brasil, e-mail: lucianadt@gmail.com
} 
Os gráficos de Bland-Altman demonstraram concordância entre os testes para identificar parâmetros metabólicos e fisiológicos no pico do exercício. Conclusão: O teste de caminhada de seis minutos induziu respostas ventilatórias, metabólicas e cardiovasculares concordantes com as do teste máximo, provando ser importante na rotina de avaliação funcional fisioterápica de mulheres obesas.

Palavras-chave: obesidade; teste de esforço; aptidão física; fisioterapia.

Received: 12/20/2011 - Revised: 05/09/2012 - Accepted: 05/18/2012

\section{Introduction : : :}

Obesity-induced limitations of the cardiopulmonary and metabolic systems, commonly resulting in exertional dyspnea, collectively contribute to the limitations in functional capacity frequently observed in obese individuals ${ }^{1}$. In addition, the sedentary lifestyle often adopted by these individuals further compounds and contributes to impaired exercise tolerance.

Cardiopulmonary exercise testing (CPX) is considered the "gold standard" method for comprehensively assessing the response to aerobic exercise. The value of CPX data is manifold, including evaluation of exercise tolerance, quantification of impairment and disability levels, determination of the physiological mechanism(s) for exercise intolerance, and exercise prescription ${ }^{2}$. However, given the increasing recognition of the value of functional capacity assessments in numerous populations in conjunction with acknowledgement of the difficulty in broadly applying CPX, there is a need for valid and reliable exercise testing assessments that can be implemented in a time- and costefficient manner ${ }^{3}$. The six-minute walking test (6MWT) is a well-established functional assessment ${ }^{4}$ that may provide a reasonable estimation of functional capacity in obese patients $^{5,6}$, even with associated diseases ${ }^{7}$. However, more work is needed in this area to validate initial findings.

Some authors have found a significant correlation between 6MWT distance and peak oxygen uptake $\left(\mathrm{VO}_{2}\right)$ measured by CPX in patients with advanced heart failure ${ }^{8}$. However, no previous study has evaluated the clinical significance of the 6MWT exercise measures comparable to CPX results in obese women. As $\mathrm{VO}_{2}$ peak is the "gold standard" measure of aerobic capacity, it seems worthwhile to determine if cardiopulmonary, metabolic, and perceptual responses to the 6MWT are in concordance with CPX outcomes in obese women. When the population undergoing functional assessment requires closer monitoring of physiological variables, performing the 6MWT on a treadmill (tread6MWT) may be particularly attractive. This approach has been previously applied in healthy subjects and in certain patient populations ${ }^{9-11}$, not including female obese patients. Therefore, the aim of this study was to analyze and compare the cardiopulmonary, metabolic, and perceptual responses to CPX and tread6MWT in obese and eutrophic women. The ultimate goal was to apply a submaximal test that could be easily used in a physical therapy clinical setting as part of the routine evaluation of obese women. We hypothesized that the tread6MWT is related to CPX in obese women and that it would elicit cardiopulmonary and metabolic responses in agreement with CPX responses.

\section{Method : :}

\section{Design and study population}

The current investigation is an observational, crosssectional, comparative study. Subjects were sedentary females, from 20 to 45 years of age, allocated to an obese group (OG): $\mathrm{BMI} \geq 30 \mathrm{~kg} \cdot \mathrm{m}^{-2}$ and weight stable for the past one year; or eutrophic group (EG): $18.5 \leq \mathrm{BMI} \leq 24.9 \mathrm{~kg} \cdot \mathrm{m}^{-2}$. Exclusion criteria were: pregnancy; currently smoking or abstinence from smoking less than one year prior to study initiation; alcohol or drug addiction; presence of diabetes; uncontrolled hypertension; diagnosis of cardiopulmonary disease, such as coronary artery disease; chronic obstructive pulmonary disease or asthma; neurological or orthopedic dysfunctions; and/or the use of $\beta$-blockers. The experimental procedures were performed respecting a minimum resting period of 48h: (a) $1^{\text {st }}$ Visit: clinical and physical therapy evaluations (anamnesis, anthropometric measures, regular physical activity pattern investigation, pulmonary function evaluation, bioelectrical impedance analysis); (b) $2^{\text {nd }}$ Visit: CPX on a treadmill; and (c) $3^{\text {rd }}$ Visit: tread6MWT performance. Approval by the institutional Ethics Committee at Universidade Federal de São Carlos (UFSCar), São Carlos, SP, Brazil (Approval 230/2009) and written informed consent from all subjects were obtained before the study initiation. 


\section{Measures}

\section{Physical therapy evaluations}

Anthropometric data (body weight, height, and BMI) was evaluated according to methodology previously described ${ }^{12}$. Regular physical activity patterns were collected by the modified Baecke questionnaire for epidemiological studies, which was previously validated in Portuguese ${ }^{13}$. Occupation, sports activities, and leisure habits were quantified to assess the physical activity patterns.

Foot-to-foot bioelectrical impedance analysis was assessed with the Tanita body composition analyzer (model TBF-310; Tanita Corp., Tokyo, Japan), which calculates fat mass, fat-free mass, percentage of fat. This set has been used previously to assess obese women ${ }^{14}$. Subjects were measured in the morning in bathing suits without shoes or any kind of metal in contact with their bodies. The subjects were advised to be in absolute fast for at least four hours as well as to urinate prior to the assessment of body composition.

Spirometric tests were performed using the ergospirometry system (Oxycon Mobile ${ }^{\circledR}$, Mijnhardt/Jäger, Würzburg, German) with flow measurement carried out using a calibrated pneumotachograph. The subjects completed at least three acceptable maximal forced and slow expiratory maneuvers according to the recommendations of the American Thoracic Society ${ }^{15}$.

\section{Experimental protocols}

All of the experimental procedures described above were performed during the afternoon to avoid the influence of circadian changes, in a climate-controlled room with temperature between $22-24^{\circ} \mathrm{C}$ and relative air humidity between $40-60 \%$. The subjects received orientation on the experimental protocols and were instructed to abstain from caffeine, stimulants and alcoholic beverages during the $24 \mathrm{~h}$ preceding the tests, avoid strenuous physical activities for $24 \mathrm{~h}$ before the experiment, to have a good night's sleep, and to ingest a light meal at least $2 \mathrm{~h}$ prior to the exercise tests. To further standardize the assessment and eliminate potential confounders, the subjects performed the tests during the follicular phase of their menstrual cycle.

\section{Cardiopulmonary exercise testing}

Symptom-limited CPX was performed on a treadmill (Master ATL, Inbramed, Porto Alegre, RS, Brazil). The exercise test consisted of: a) 4-min rest at standing position on the treadmill; b) incremental phase according to the Bruce ramp protocol ${ }^{12}$; ) 3 -min recovering period. All the subjects were actively encouraged by the investigators in a standardized fashion throughout the test to walk and/or run to the limit of tolerance. Heart rate (HR), arterial blood pressure (ABP) measured using a standard cuff sphygmomanometer (Diasyst ${ }^{\circledR}$, São Paulo, Brazil) and perceived exertion by Borg scale ${ }^{16}$ were measured at each stage of exercise protocol, and throughout the recovering period.

Ventilatory expired gases were continuously measured during CPX and analyzed breath-by-breath using an ergoespirometric system (Oxycon Mobile ${ }^{\circledR}$, Mijnhardt/Jäger, Würzburg, German), which was calibrated before each test according to manufacturer specifications. Patients were also monitored using a thoracic MC5 lead (cardiac monitor Ecafix TC500, São Paulo, SP, Brazil). Test termination criteria followed American Thoracic Society recommendations ${ }^{2}$. Two qualified physical therapists with physician supervision conducted each exercise test.

Aerobic capacity was evaluated using $\mathrm{VO}_{2}$ data obtained at the peak of exercise. Metabolic and ventilatory data were processed and calculated in mobile averages, every eight breathing cycles. The average value the last $15 \mathrm{~s}$ was defined as the subject's peak $\mathrm{VO}_{2}$ and peak respiratory exchange ratio (RER). Visual analyses of breathing and metabolic responses were made by three duly trained observers in order to determine ventilatory anaerobic threshold (VAT). The V-slope method was used to determine VAT through consensus of three experienced reviewers ${ }^{17}$.

\section{Treadmill Six-Minute Walking Test}

The tread6MWT was performed on a treadmill with zero inclination and subject-controlled speed ${ }^{18}$. Subjects began at a speed of $3 \mathrm{~km} \cdot \mathrm{h}^{-1}$. They were instructed and encouraged to walk as far as possible, according to American Thoracic Society guidelines ${ }^{4}$. In addition, they were allowed to increase or decrease the speed of the treadmill at any time, according to symptoms of fatigue or dyspnea. Heart rate and perceived exertion by the Borg scale ${ }^{16}$ were measured every three minutes and at the exercise peak. The subjects' ABP was measured at rest in the standing position on the treadmill as well as at the exercise peak and throughout their recovery period. The treadmill's data panel showing speed and distance covered was not visible to the subject; only the start, stop, and speed up or slow down buttons were accessible to them. The subjects were allowed to interrupt the test if they had symptoms such as tachycardia or any discomfort that would make it impossible for them to continue the test. Two tests were completed with a minimum interval of one hour in order to reduce learning effects. Only the outcomes from the second tread6MWT were considered for statistical analysis.

\section{Statistical analysis}

The sample size was calculated using ENE software, version 2.0 (GlaxoSmithKline España S.A., Madrid, Spain, and 
Universidad Autónoma de Barcelona, Barcelona, Spain). The target sample size was calculated to be four in each group considering a $5 \%$ type I error, a 2 -sided test, and an $80 \%$ power to detect a significant difference of $\mathrm{VO}_{2}=12.9 \mathrm{~mL} \cdot \mathrm{kg}^{-1} \cdot \mathrm{min}^{-1}$ at the maximal metabolic rate in obese and normal weight subjects ${ }^{19}$. The analysis was performed with MedCalc statistical software, Version 11.4.4.0 (MedCalc Software, Mariakerke, Belgium). Data are presented as mean \pm SD after testing for normal distribution (Shapiro-Wilk test) and as median (minimum, maximum) for categorical variables. The Student unpaired $t$-test was used for the comparison of continuous demographic and anthropometric data, bioelectrical impedance indexes, lung function, symptom data, and CPX and tread6MWT outcomes between the OG and the EG. The Student paired $t$-test was used to compare CPX and tread6MWT outcomes in each studied group. Fisher's exact test was used to compare the medication intake between groups. The relationship between relative $\mathrm{VO}_{2}\left(\mathrm{~mL} \cdot \mathrm{kg}^{-1} \cdot \mathrm{min}^{-1}\right)$ and $\mathrm{BMI}$ in CPX and the tread 6MWT as well as the correlation between $\mathrm{HR}_{\text {peak }}$ and $\mathrm{VO}_{2}\left(\mathrm{~mL} \cdot \mathrm{min}^{-1}\right)$ were assessed using Pearson's correlation. The stepwise regression was analyzed considering $\mathrm{HR}_{\text {peak }}$ in both tests. Moreover, the absolute limits of agreement between the metabolic and cardiovascular variables assessed by CPX and the tread6MWT were evaluated by the Bland-Altman analysis ${ }^{20}$. The probability of a type I error was set at $5 \%(p<0.05)$.

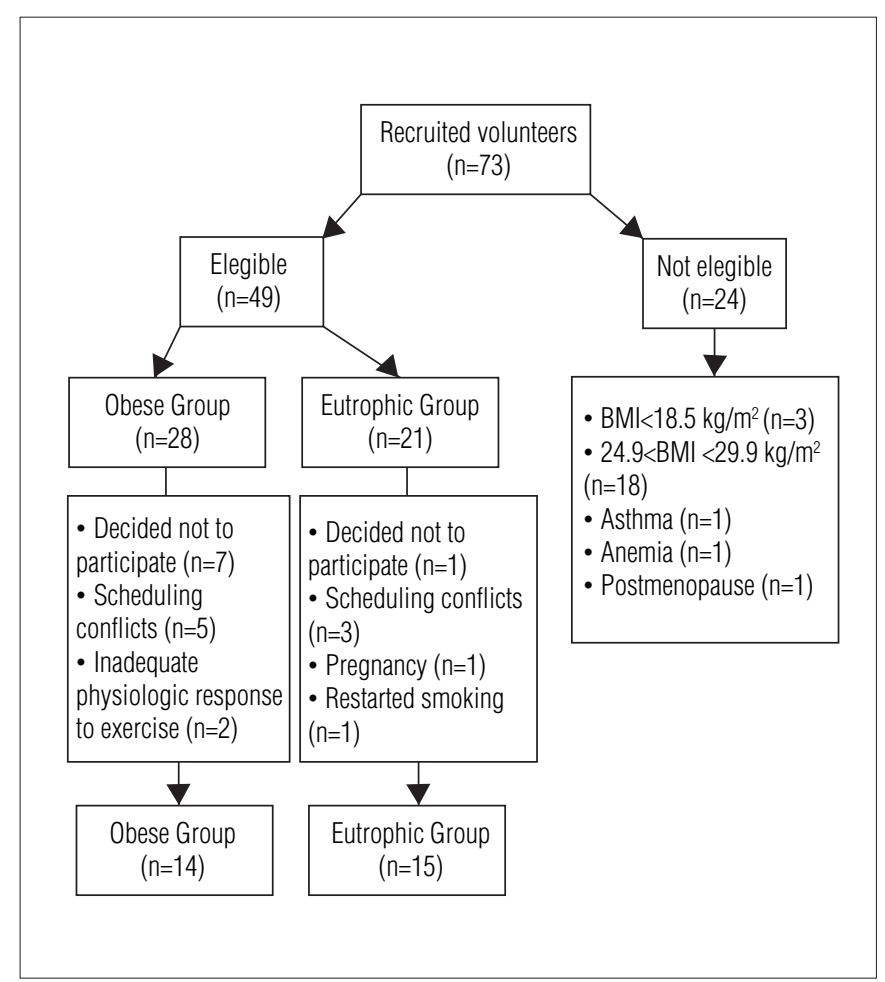

Figure 1. Flowchart - sample loss of each group.

\section{Results : :}

Seventy-three subjects were recruited. Figure 1 illustrates the attrition rate of each group. Table 1 lists demographic and anthropometric data, cardiovascular parameters at rest, bioelectrical impedance indexes, current medications, and lung function of both groups. Significant differences between groups were found regarding weight, BMI, HR, systolic and diastolic ABP (SBP and DBP, respectively), and body composition data. There were no differences in medication intake between groups. Three obese subjects presented with controlled hypertension and two eutrophics presented with controlled hypothyroidism. Data from spirometry confirmed exclusion criteria and no difference was found between the OG and the EG (Table 1). All women were considered to be sedentary according to Baecke questionnaire results, with a total score at or below 8: seven obese women had scores below 6 while the other half had scores between 6 and 8; four eutrophics had scores below 6 , and eleven had scores between 6 and 8 . Nevertheless, there were no significant differences between groups $(p=0.26)$.

\section{Exercise-related physiological and subjective responses}

Table 2 shows CPX and tread6MWT results. All patients were able to successfully complete both tests without complications, except two obese subjects that presented inadequate $\mathrm{ABP}$ response to exercise during CPX and were excluded from the final sample. The test duration of CPX as well as the speed reached and the distance covered in both tests were significantly lower in the OG compared to the EG.

As expected, in both tests, obese women had higher absolute values for $\mathrm{VO}_{2}(\mathrm{p}<0.0001)$ compared to eutrophics but, when $\mathrm{VO}_{2}$ were corrected by weight, they were significantly lower $(p=0.02)$ in the OG. Moreover, minute ventilation, SBP, and DBP were higher in the OG. There were no differences in $\mathrm{RR}$, leg fatigue, $\mathrm{VE} / \mathrm{VO}_{2}$ or $\mathrm{VE} / \mathrm{VCO}_{2}$ between groups.

In relation to the maximal test, peak RER was lower and dyspnea symptoms were significantly higher in the OG compared to the EG. There were no differences in percent-predicted peak $\mathrm{VO}_{2}$, tidal volume, $\mathrm{HR}$, and the percent-predicted $\mathrm{HR}\left(\% \mathrm{HR}\right.$ ) between groups. Regarding the tread6MWT, $\mathrm{VCO}_{2}$, tidal volume, HR, and \%HR were all higher in the OG compared to the EG.

Table 2 also shows the comparison between integrative responses to CPX vs. tread6MWT. CPX induced a higher 
Table 1. Demographic, anthropometric, and body composition data; baseline cardiovascular variables; current medications; and lung function of each group.

\begin{tabular}{|c|c|c|c|}
\hline & Eutrophic Group $(n=15)$ & Obese Group $(n=14)$ & $p$ value \\
\hline Age, years & $30 \pm 7$ & $33 \pm 8$ & 0.44 \\
\hline Height, m & $1.66 \pm 7$ & $1.62 \pm 7$ & 0.19 \\
\hline Weight, kg & $60.5 \pm 8$ & $100.4 \pm 16$ & $<0.0001$ \\
\hline $\mathrm{BMI}, \mathrm{kg} \cdot \mathrm{m}^{-2}$ & $22 \pm 2$ & $38 \pm 6$ & $<0.0001$ \\
\hline Heart rate, bpm & $85 \pm 8$ & $93 \pm 12$ & 0.04 \\
\hline Fat $\%$ & $27 \pm 5$ & $46 \pm 4$ & $<0.0001$ \\
\hline Fat mass, $\mathrm{kg}$ & $17 \pm 5$ & $47 \pm 11$ & $<0.0001$ \\
\hline Fat-free mass, $\mathrm{kg}$ & $44 \pm 3$ & $54 \pm 6$ & 0.0002 \\
\hline SBP, mmHg & $109 \pm 9$ & $119 \pm 12$ & 0.01 \\
\hline $\mathrm{DBP}, \mathrm{mmHg}$ & $75 \pm 8$ & $86 \pm 8$ & $<0.01$ \\
\hline Contraceptive & 4 & 6 & 0.45 \\
\hline Angiotensin II receptor antagonists & 0 & 2 & 0.22 \\
\hline Diuretic & 0 & 1 & 0.48 \\
\hline Thyroid-stimulating hormone & 2 & 0 & 0.22 \\
\hline FVC, L & $3.7 \pm 0.7$ & $3.4 \pm 0.6$ & 0.31 \\
\hline FVC, \% pred & $93.1 \pm 11.9$ & $92.7 \pm 12.6$ & 0.93 \\
\hline $\mathrm{FEV}_{1}, \mathrm{~L}$ & $3.3 \pm 0.6$ & $2.9 \pm 0.5$ & 0.09 \\
\hline $\mathrm{FEV}_{1}, \%$ pred & $97.8 \pm 13.0$ & $94.3 \pm 12.5$ & 0.46 \\
\hline $\mathrm{FEV}_{1} / \mathrm{FVC}$ & $88.8 \pm 4.0$ & $85.3 \pm 5.4$ & 0.07 \\
\hline $\mathrm{FEV}_{1} / \mathrm{FVC}, \%$ pred & $105.1 \pm 4.0$ & $101.7 \pm 6.1$ & 0.10 \\
\hline
\end{tabular}

Data presented as mean \pm SD. BMl: body mass index; Fat\%: percentage of total body fat mass; FVC: forced vital capacity; FEV $\mathrm{f}_{1}$ forced expiratory volume in one second. (Student unpaired $t$-test or Fisher's exact test, when appropriate; $p<0.05)$.

increment in the majority of the test outcomes for the OG, except distance walked, $\mathrm{VE} / \mathrm{VCO}_{2}$, DBP, and perceived leg fatigue. In contrast, CPX induced a higher increment in most of the variables of the EG, except walking speed and $\mathrm{VE} / \mathrm{VO}_{2}$ ratio.

At VAT during CPX, markedly lower values were found in the OG compared to the EG for time, treadmill speed, and relative peak $\mathrm{VO}_{2}$ as were higher absolute values for $\mathrm{VO}_{2}, \mathrm{VCO}_{2}$, VE, and $\mathrm{RR}$. There were no differences between groups in relation to the other metabolic and ventilatory parameters at VAT.

Considering all the subjects, absolute $\mathrm{VO}_{2}$ peak $\left(\mathrm{L} \cdot \mathrm{min}^{-1}\right)$ during CPX was modestly correlated $(r=0.53)$ to the same parameter of the tread6MWT (Figure 2A). In addition, a strong positive correlation ( $\mathrm{r}=0.77$ ) was found between $\mathrm{HR}_{\text {peak }}$ during CPX and the tread6MWT in the OG (Figure 2B). Figure 2C shows a stepwise regression analysis $(\mathrm{y}=-66.9299+1.2324 \mathrm{x})$ between $\mathrm{HR}_{\text {peak }}$ in both tests $\left(\mathrm{r}^{2}=0.58 ; \mathrm{p}=0.001\right)$.

\section{Agreement between CPX and the tread6MWT}

Analysis of agreement between both exercise tests applied to assess functional capacity was carried out by a Bland-Altman plot. Considering the metabolic and ventilatory parameters reached in the CPX as the "gold standard," we chose CPX-peak $\mathrm{VO}_{2}$ vs. tread6MWT-peak $\mathrm{VO}_{2}$ and CPX-VE vs. tread6MWT-VE to plot as primary variables of interest.
Two additional secondary variables from CPX were selected as well: CPX-SBP vs. tread6MWT-SBP and CPX-peak HR vs. tread6MWT-peak HR. As reported in Figures 3A and 3B, the mean of the differences to identify the relative $\mathrm{VO}_{2}$ and the VE by CPX and the tread6MWT was $6.0 \pm 5.6 \mathrm{~mL} \cdot \mathrm{kg}^{-1} \cdot \mathrm{min}^{-1}$ and $29.0 \pm 16.9$ L. $\mathrm{min}^{-1}$, respectively. Similarly, the agreement of both tests to identify SBP and HR at the peak of exercise calculated by the Bland-Altman method found a mean difference between the tests of $17.5 \pm 19.4 \mathrm{mmHg}$ and $32.9 \pm 19.4$ beats per minute (Figures 3C and 3D), respectively. Therefore, there was agreement between the tests in all performed analysis.

\section{Discussion $: \because$.}

In this study, we demonstrated that the submaximal tread6MWT promoted cardiorespiratory and metabolic responses in agreement with CPX in obese women, thus showing the advantage of lower cardiopulmonary and metabolic stress as well as lower perceived dyspnea during the test. Therefore, it is possible to predict the $\mathrm{HR}_{\text {peak }}$ of the symptom-limited CPX by means of the $\mathrm{HR}_{\text {peak }}$ reached in the tread6MWT. Additionally, the exercise tests demonstrated a lower functional capacity in obese women in comparison with eutrophics, expressed by metabolic, ventilatory, and cardiovascular variables and dyspnea perception, as well as speed and walking distance. 
Table 2. Maximal cardiopulmonary exercise test (CPX) and treadmill six-minute walking test (tread6MWT) data at the peak of the tests and at the anaerobic threshold.

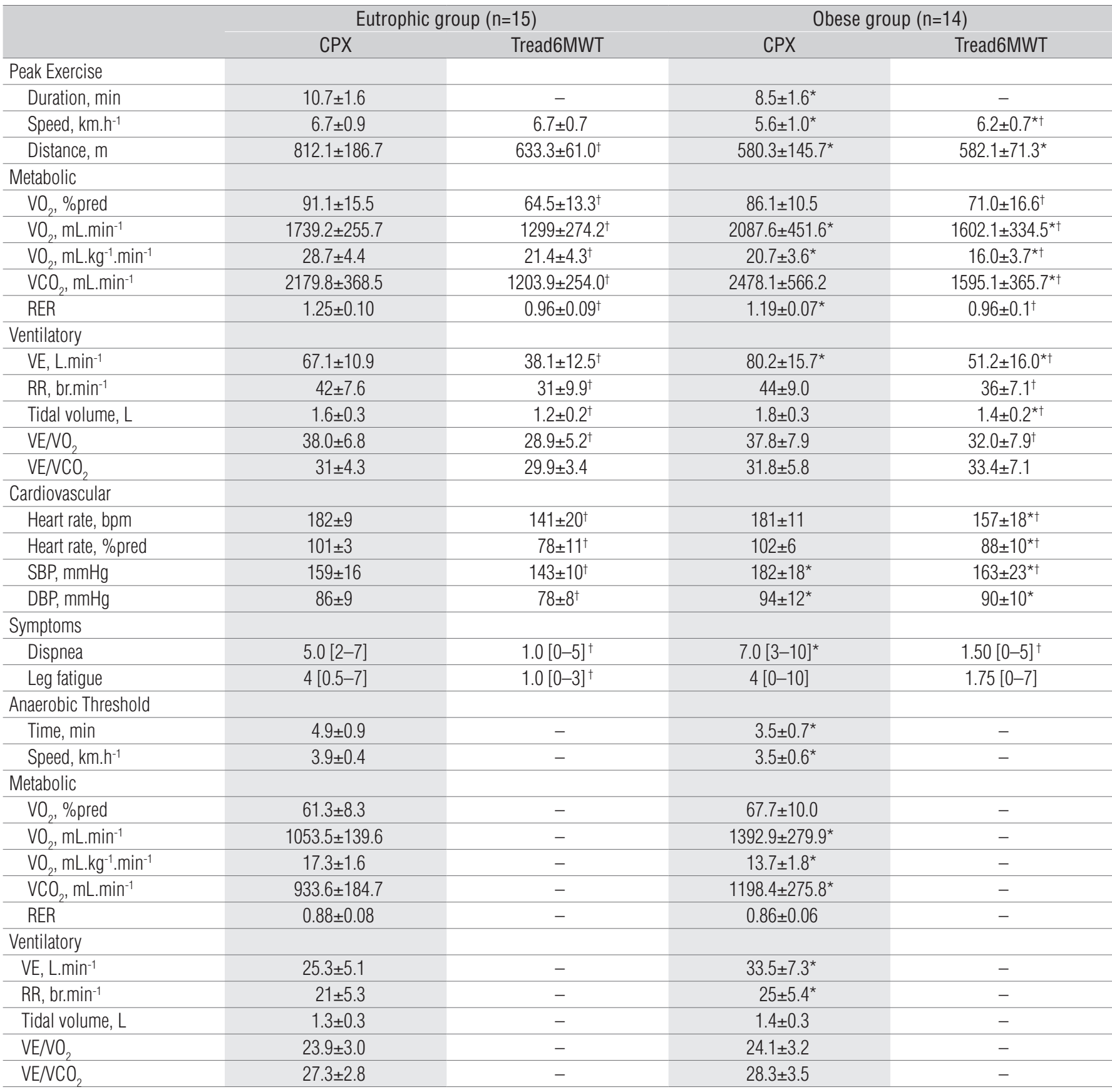

Data presented as mean $\pm \mathrm{SD}$ or median \pm [minimum, maximum] when appropriate. V $\mathrm{O}_{2}$ : oxygen uptake; $\mathrm{VCO}_{2}$ : carbon dioxide production; RER: respiratory exchange rate; VE: minute ventilation; RR: respiratory

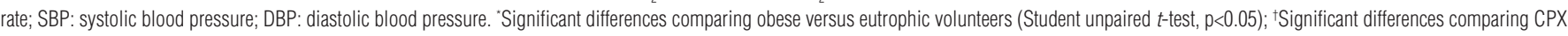
versus tread6MWT (Student paired $t$-test, $\mathrm{p}<0.05$ ).

\section{Comparison between CPX and tread6MWT outcomes}

Because the 6MWT is better tolerated than CPX by individuals with disabilities and because it has been used to evaluate functional capacity in several populations ${ }^{21}$, we compared exercise responses between tests. It is well known that CPX is considered the "gold standard" to assess the integrative exercise response since it is a progressive exercise to the tolerance limit that combines the assessment of ECG, hemodynamic, subjective symptoms and ventilatory expired gas analysis measures ${ }^{2}$. Another advantage of the CPX is that it is applied on an ergometer, which allows for the collection of the aforementioned variables while controlling for workload titration. However, the time required, the need for specially trained staff, and the cost of the equipment limits the widespread applicability of CPX.

Interestingly, although the 6MWT is usually applied in a corridor to obtain a more secure monitoring of the physiological 
parameters, it can also be applied on a treadmill ${ }^{11}$. This was one of the reasons for choosing the tread6MWT, the other reason being to collect ventilatory expired gas variables with the same equipment used during CPX for comparative purposes. Guimarães, Carvalho and Bocchi ${ }^{18}$ applied the tread6MWT with ventilatory expired gas monitoring in heart failure patients and found it to be a feasible approach to functional assessment in this population. Despite the previous application of the tread6MWT in healthy subjects and certain patient populations, we acknowledge that tread6MWT distance results are not interchangeable with corridor tests ${ }^{4,11}$.

Some studies have shown correlation and regression analysis to complement Bland-Altman method-comparison plots of agreement ${ }^{22}$. In this way, besides the demonstrated agreement between CPX and the tread6MWT through Bland-Altman analysis, the linear regression showed the $\mathrm{HR}_{\text {peak }}$ in CPX could be predicted by means of $\mathrm{HR}_{\text {peak }}$ reached in the tread6MWT. Thus, although CPX and the tread6MWT measure different aspects of exercise tolerance, the second test becomes an adjunct method in physical therapy evaluation when CPX is not available.

It is well known that obese individuals consume a greater amount of oxygen compared to eutrophics at the same external work load due to their increased body mass. ${ }^{4}$. In our results, the OG showed a decreased work capacity compared to the EG since the former reached VAT earlier and had a lower CPX duration with higher $\mathrm{VO}_{2}$ absolute values. This metabolic behavior may be consequence of a lower tolerability to exercise as a result of the increase in arterial lactate with subsequent metabolic acidosis in obese individuals compared to normal weight individuals.

Hulens et al. ${ }^{23}$ applied a maximal exercise test on a cycle ergometer to a large sample of obese and lean women. They demonstrated that exercise capacity in the obese population was decreased as evidenced by lower relative $\mathrm{VO}_{2}$, VE, HR, and RER compared to the lean subjects. Other authors ${ }^{24}$ also demonstrated reduced physical fitness and functional capacity during CPX in obese women compared to normal weight and overweight women. These findings are in accordance with the results of the present study and corroborate the deleterious impact that excess body weight has on physical function and, ultimately, prognosis ${ }^{25}$.

Comparing the walking distance in both tests, the OG covered a shorter distance than the EG. However, the OG covered a greater distance during the tread6MWT compared to the CPX, which may be attributed to the self-selection of walking speed and lower physical requirements. Regarding the submaximal test, several studies have demonstrated shorter 6MWT distances covered by obese individuals, with an increase in distances after weight loss and/or aerobic training ${ }^{6,12}$.

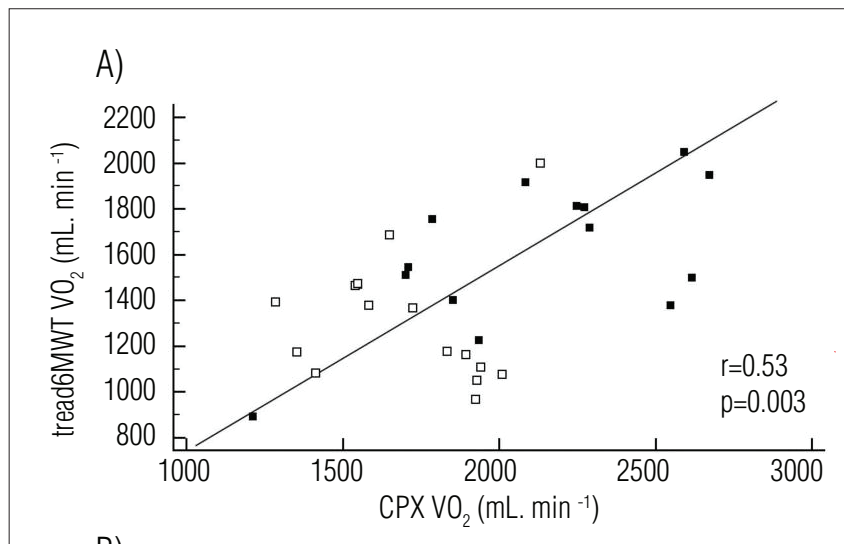

B)

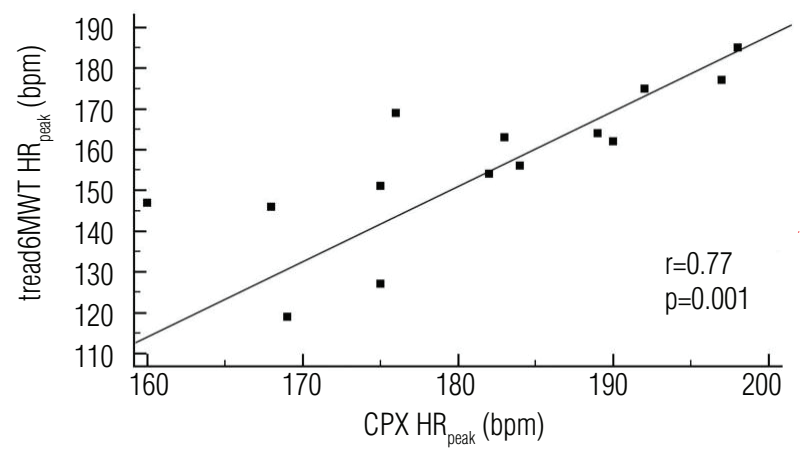

C)

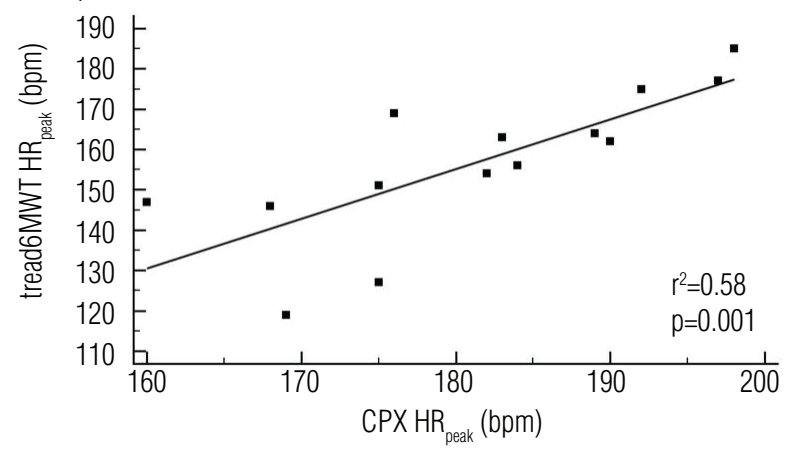

Tread6MWT; six-minute walking test on a treadmill; CPX: cardiopulmonary exercise testing; $\mathrm{VO}_{2}$ : oxygen uptake; HR: heart rate. Obese group (black squares) and eutrophic group (white squares).

Figure 2. (A) Correlation between peak $\mathrm{VO}_{2}$ in both tests in studied groups; (B) Correlation between Peak HR in both tests - tread6MWT and CPX - in obese women; $(\mathrm{C})$ Linear regression considering $\mathrm{HR}_{\text {peak }}$ in both tests in obese women.

Although pulmonary function evaluated by spirometry remains relatively normal compared to predicted values and no relevant impairment in pulmonary gas exchange occurs in obese women during exercise ${ }^{1}$, they present with a blunted hyperventilation response during intense exercise ${ }^{25,26}$. Our results confirmed these previous findings since our obese women did not elevate their respiratory rate proportionally to the significantly higher absolute $\mathrm{VO}_{2}$ peak compared to the EG as demonstrated in Table 2. This inadequate behavior could be related to the perceived dyspnea by the OG during CPX exercise peak and to the oxygen cost of breathing in 
A)

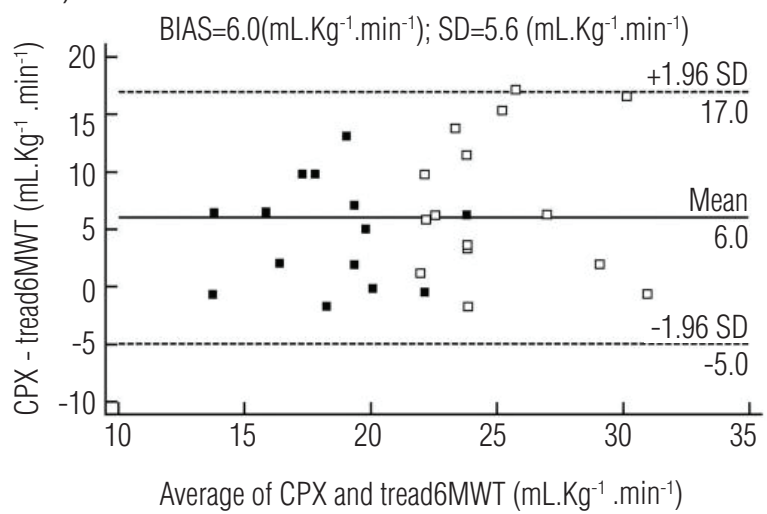

C)

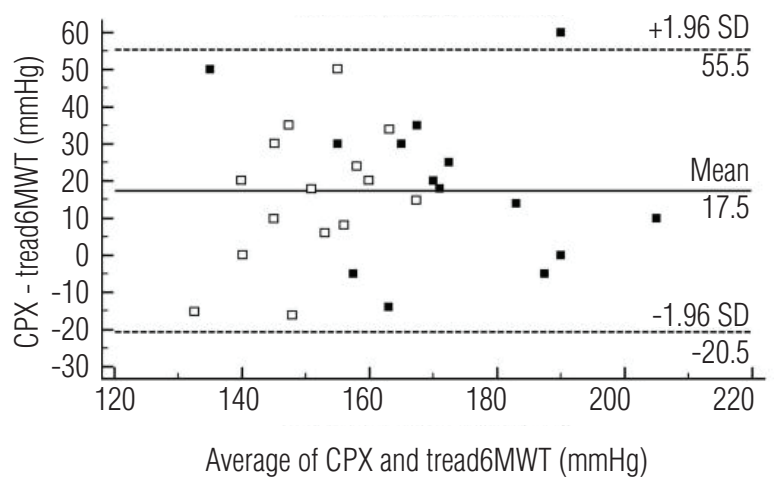

B)

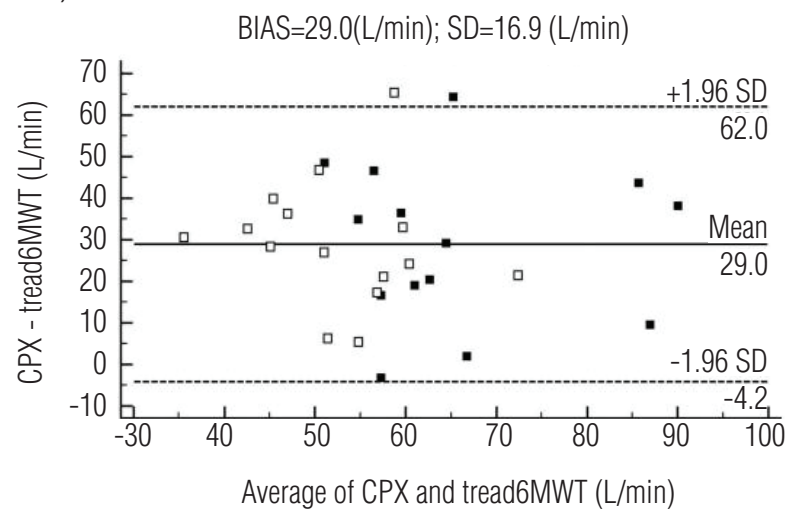

D)

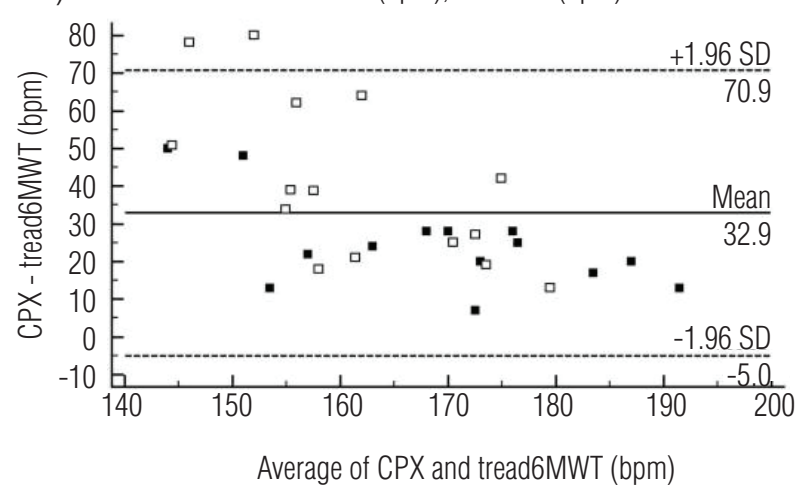

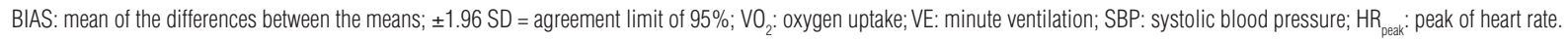

Figure 3. Bland-Altman plots show agreement of means difference: (A) VO ${ }_{2}\left(\mathrm{~mL}^{\mathrm{kg}} \mathrm{kg}^{-1} \cdot \mathrm{min}^{-1}\right)$; (B) VE (L.min-1); (C) SBP (mmHg); (D) HR $\mathrm{R}_{\text {peak }}$ (bpm).

obese individuals, which can be almost threefold higher (at $3.45 \mathrm{~mL}$ of oxygen per liter of ventilation) than eutrophics ${ }^{27}$. $\mathrm{VE} / \mathrm{VCO}_{2}$ ratio reflects the ventilatory efficiency but we found no difference between groups. In contrast with our findings, others authors ${ }^{28}$ have described a decreased mean ventilatory efficiency, which increased after a 12-week functional exercise program in obese women, although not to sedentary healthy levels. Future studies are necessary to better investigate ventilatory efficiency in obesity, even at different levels of this disease, including $\mathrm{VE} / \mathrm{VO}_{2}$ slope during maximal and submaximal exercise tests.

In our study, obese women had higher SBP and DBP compared to eutrophics at rest and during both exercise tests. However, the consequences of obesity on cardiac function remain unclear. Some authors have described alterations in systolic or diastolic function ${ }^{29}$, with diastolic abnormalities representative of the early cardiac consequences of obesity ${ }^{30}$, while other researchers have pointed out normal cardiac function in obese individuals ${ }^{31}$. Similarly to our results, Séres et al. ${ }^{32}$ found higher ABP values in morbidly obese individuals than in controls at rest and during a symptom-limited CPX.

\section{Clinical implications}

The high energy output required to move total body mass leads obese women to have reduced exercise capacity ${ }^{32}$. Moreover, dyspnea during exercise is a common complaint in this population ${ }^{1}$ which could limit their performance in a maximal symptom-limited exercise test. For this reason, we decided to comprehensively assess the response to exercise to confirm a submaximal test (i.e. tread6MWT) could be used as a reasonable method to evaluate functional capacity with ventilatory, metabolic, cardiovascular, and perceptual responses in agreement with CPX. In addition, HR responses of the tread6MWT applied in the present study can predict 
maximal HR responses. That result is very important given that the submaximal test allows the physical therapist to prescribe the intensity of rehabilitation programs in the obese population without submitting those patients to maximal stress testing.

Thus, ABP and HR measures are variables easily assessed during the tread6MWT and, as the Bland-Altman plot has shown, they have a good level of agreement between CPX and the submaximal test, a finding which supports the clinical utility of the $6 \mathrm{MWT}$ in this patient population.

\section{Study limitations}

Some limitations of this study should be mentioned. We evaluated only the female obese population due to their adherence to the protocol and their availability to schedule visits. However, more studies are necessary to assess obese men. Although the 6MWT is usually applied in a corridor, we reproduced it on a treadmill to apply the same ergometer used in CPX.

\section{Conclusions : $: \therefore$}

The tread6MWT promoted ventilatory, metabolic, and cardiovascular responses in agreement with CPX. Additionally, it may prove to be an adequate submaximal exercise test for functional evaluation of obese women in the physical therapy routine without imposing maximal stress or a perceived dyspnea level as high as the one imposed by symptom-limited CPX.

\section{Acknowledgements : :}

The Fundação de Amparo à Pesquisa do Estado de São Paulo (FAPESP 2009/01842-0) São Paulo, SP, Brazil and Coordenação de Aperfeiçoamento de Pessoal de Nível Superior (CAPES), Brasília, DF, Brazil for funding this study. The Vilmar Baldissera of the Laboratory of Exercise Physiology, Biology Department, at UFSCar, for kindly lending us the body composition analyzer. More importantly, however, we are indebted to the participants for their cooperation throughout the study.

\section{References $: \because$.}

1. Zavorsky GS. Cardiopulmonary aspects of obesity in women. Obstet Gynecol Clin North Am. 2009;36(2):267-84

2. American Thoracic Society; American College of Chest Physicians. ATS/ACCP Statement on cardiopulmonary exercise testing. Am J Respir Crit Care Med. 2003;167(2): 211-77.

3. Pires SR, Oliveira AC, Parreira VF, Britto RR. Teste de caminhada de seis minutos em diferentes faixas etárias e índices de massa corporal. Rev Bras Fisioter. 2007;11(2):147-151.

4. ATS Committee on Proficiency Standards for Clinical Pulmonary Function Laboratories. ATS statement: guidelines for the six-minute walk test. Am J Respir Crit Care Med. 2002;166(1): $111-7$.

5. Perecin JC, Domingos-Benício NC, Gastaldi AC, Sousa TC, Cravo SLD, Sologuren MJJ. Teste de caminhada de seis minutos em adultos eutróficos e obesos. Rev Bras Fisioter. 2003;7(3):245-51.

6. Maniscalco M, Zedda A, Giardiello C, Faraone S, Cerbone MR, Cristiano S, et al. Effect of bariatric surgery on the six-minute walk test in severe uncomplicated obesity. Obes Surg. 2006;16(7):836-41

7. Vasconcelos KSS, Dias JMD, Dias RC. Relationship between pain intensity and functional capacity of obese individuals with knee osteoarthritis. Rev Bras Fisioter. 2006;10(2):213-8.

8. Cahalin LP, Mathier MA, Semigran MJ, Dec GW, DiSalvo TG. The six-minute walk test predicts peak oxygen uptake and survival in patients with advanced heart failure. Chest. 1996;110(2): 325-32.

9. Camargo VM, Martins Bdo C, Jardim C, Fernandes CJ, Hovnanian A, Souza R. Validation of a treadmill six-minute walk test protocol for the evaluation of patients with pulmonary arterial hypertension. J Bras Pneumol. 2009;35(5):423-30.

10. Prochaczek F, Winiarska H, Krzyzowska M, Brandt JS, Swida KR, Szczurek ZW, et al. Six-minute walk test on a special treadmill: Primary results in healthy volunteers. Cardiol J. 2007;14(5): 447-52.

11. Stevens D, Elpern E, Sharma K, Szidon P, Ankin M, Kesten S. Comparison of hallway and treadmill six-minute walk tests. Am J Respir Crit Care Med. 1999;160(5 Pt 1):1540-3.
12. Castello V, Simões RP, Bassi D, Catai AM, Arena R, Borghi-Silva A. Impact of aerobic exercise training on heart rate variability and functional capacity in obese women after gastric bypass surgery. Obes Surg. 2011;21(11):1739-49.

13. Florindo AA, Latorre MRD, Jaime PC, Tanaka T, Zerbini CAF. Metodologia para a avaliação da atividade física habitual em homens com 50 anos ou mais. Rev Saúde Pública 2004;38(2):307-14.

14. Minderico CS, Silva AM, Keller K, Branco TL, Martins SS, Palmeira AL, et al. Usefulness of different techniques for measuring body composition changes during weight loss in overweight and obese women. Br J Nutr. 2008;99(2):432-41.

15. Lung function testing: selection of reference values and interpretative strategies. American Thoracic Society. Am Rev Respir Dis. 1991;144(5):1202-18.

16. Borg GA. Psychophysical bases of perceived exertion. Med Sci Sports Exerc 1982;14(5):377-81.

17. Beaver WL, Wasserman $\mathrm{K}$, Whipp BJ. A new method for detecting anaerobic threshold by gas exchange. J Appl Physiol. 1986;60(6):2020-7.

18. Guimarães GV, Carvalho VO, Bocchi EA. Reproducibility of the self-controlled six-minute walking test in heart failure patients. Clinics (Sao Paulo). 2008;63(2):201-6.

19. Browning RC, Kram R. Energetic cost and preferred speed of walking in obese vs. normal weight women. Obes Res. 2005:13(5):891-9.

20. Bland JM, Altman DG. Statistical methods for assessing agreement between two methods of clinical measurement. Lancet. 1986;1(8476):307-10

21. Miyamoto S, Nagaya N, Satoh T, Kyotani S, Sakamaki F, Fujita M, et al. Clinical correlates and prognostic significance of six-minute walk test in patients with primary pulmonary hypertension. Comparison with cardiopulmonary exercise testing. Am J Respir Crit Care Med. 2000;161(2 Pt1): 487-92.

22. Dewitte K, Fierens C, StöckI D, Thienpont LM. Application of the Bland-Altman plot for interpretation of method-comparison studies: a critical investigation of its practice. Clin Chem. 2002:48(5):799-801 
23. Hulens M, Vansant $G$, Lysens $R$, Claessens AL, Muls E. Exercise capacity in lean versus obese women. Scand J Med Sci Sports. 2001;11(5):305-9.

24. Fornitano LD, Godoy MF. Exercise testing in individuals with morbid obesity. Obes Surg. 2010;20(5):583-8

25. Zavorsky GS, Murias JM, Kim do J, Gow J, Christou NV. Poor compensatory hyperventilation in morbidly obese women at peak exercise. Respir Physiol Neurobiol. 2007;159(2): 187-95.

26. Zavorsky GS, Hoffman SL. Pulmonary gas exchange in the morbidly obese. Obes Rev. 2008:9(4):326-39

27. Babb TG. Mechanical ventilatory constraints in aging, lung disease, and obesity: perspectives and brief review. Med Sci Sports Exerc. 1999:31(1 Suppl): S12-22.
28. Castres I, Lemaitre F, Tardif C, Beuret-Blanquart F, Tourny-Chollet C. Dynamic cardiorespiratory changes in obese women. J Sports Med Phys Fitness. 2011;51(2):283-91.

29. Pascual M, Pascual DA, Soria F, Vicente T, Hernández AM, Tébar FJ, et al. Effects of isolated obesity on systolic and diastolic left ventricular function. Heart. 2003;89(10):1152-6.

30. Scaglione R, Dichiara MA, Indovina A, Lipari R, Ganguzza A, Parrinello G, et al. Left ventricular diastolic and systolic function in normotensive obese subjects: influence of degree and duration of obesity. Eur Heart J. 1992;13(6):738-42.

31. Chockalingam A, Linden MA, Dellsperger KC, Thomas TR. Correlation of normal diastolic cardiac function with $\mathrm{VO}_{2}$ in the metabolic syndrome. Prev Cardiol. 2009;12(3):163-8.

32. Serés L, López-Ayerbe J, Coll R, Rodríguez 0, Manresa JM, Marrugat J, et al. Cardiopulmonary function and exercise capacity in patients with morbid obesity. Rev Esp Cardiol. 2003;56(6): 594-600. 